\title{
Perfil proteico e mineral de cabras leiteiras com toxemia da prenhez subclínica acompanhadas antes, durante e após o parto
}

Rodolfo José Cavalcanti Souto[a]" Gliére Silmara Leite Soares ${ }^{[b]}$, Alexandre Tadeu Mota Macedo $0^{[a]}$, Jobson Filipe de Paula Cajueiro ${ }^{[b]}$, Rafael Otaviano do Rêgo ${ }^{[a]}$, Jomel Francisco dos Santos ${ }^{[a]}$, Pierre Castro Soares ${ }^{[l]}$,José Augusto Bastos Afonso $0^{[[]}$, Carla Lopes de Mendonçą ${ }^{[\mathrm{d}]}$

\footnotetext{
[a] Pós-Graduação em Ciência Veterinária, Universidade Federal Rural de Pernambuco (UFRPE), Recife, PE, Brasil

[b] Pós-Graduação em Sanidade e Reprodução de Ruminantes, Universidade Federal Rural de Pernambuco (UFRPE), Recife, PE, Brasil

${ }^{[c]}$ Departamento de Medicina Veterinária, Universidade Federal Rural de Pernambuco (UFRPE), Recife, PE, Brasil

[d] Clínica de Bovinos, Universidade Federal Rural de Pernambuco (UFRPE), Garanhuns, PE, Brasil
}

*Autor correspondente

e-mail: rodolfojcsouto@gmail.com

\section{Resumo}

A toxemia da prenhez (T.P), entre as doenças da produção, é a mais importante desordem metabólica em pequenos ruminantes; entretanto, a forma subclínica, que caracteriza-se pela elevação de corpos cetônicos sem a expressão nosológica da enfermidade, é pouca estudada. Este trabalho teve por objetivo avaliar as alterações sanguíneas no perfil proteico e mineral de cabras leiteiras acometidas com T.P na forma subclínica durante o período de transição. Foram acompanhadas 79 cabras leiteiras de alta produção, pluríparas, multíparas, mestiças e criadas em regime intensivo, em diferentes propriedades rurais do semiárido do estado de Pernambuco. Os animais eram vacinados e vermifugados e a alimentação era composta por bagaço de cana-de-açúcar, palma, farelo de trigo, milho, soja e algodão, além de sal mineral e água à vontade. As cabras que apresentaram valores de $\mathrm{BHB} \leq 0,8 \mathrm{mmol} / \mathrm{L}$ em todos os momentos de avaliação ( $\mathrm{n}=40)$ compuseram o grupo controle (G1), enquanto aquelas que em pelo menos um dos momentos experimentais apresentou valores de BHB entre 0,8 mmol/L a 1,6 mmol/L foram consideradas como portadoras da T.P subclínica (G2). Os animais foram avaliados clínica e laboratorialmente 30, 20, 10 dias antes do parto, momento do parto e 10, 20 e 30 dias pós-parto. Para a avaliação dos metabólitos proteico e mineral mensurou-se a albumina, ureia, cálcio ionizado, cloretos, potássio e sódio. Foi utilizada a análise de variância (Teste F) com a finalidade de averiguar os efeitos e interações entre grupos e momentos, empregando-se programa computacional SAS. Não foi observada interação entre grupos e momentos. A enfermidade subclínica durante o período de transição acarretou elevação $(\mathrm{P}<0,01)$ nos valores de potássio e decréscimo da albumina $(\mathrm{P}<0,01)$ 
e cálcio ionizado $(\mathrm{P}<0,01)$. Não foi observado efeito $(\mathrm{P}>0,05)$ da T.P subclínica sobre a ureia, cloretos e sódio. A elevação do potássio se relaciona à diminuição da concentração de insulina encontrada, por ser este hormônio o mais importante no deslocamento do potássio para o interior das células. Houve diminuição da albumina, porém uma alteração branda podendo estar relacionada à síntese hepática. A hipocalcemia encontrada é resultado da demanda para a formação do esqueleto fetal, formação de colostro e produção de leite em cabras, provavelmente associada à maior redução da ingestão de alimentos nas cabras com o transtorno metabólico subclínico. Dentre as variáveis estudadas, merecem destaque as alterações sanguíneas do potássio e do cálcio ionizado, resultante da T.P subclínica durante o período de transição. 